\title{
Title: Fatigue is the predominant patient-reported outcome measure in hemodialysis patients: Results of a multicenter cross-sectional ePROMs Study
}

Abdallah. Guerraoui ( $\sim$ abdallah.guerraoui@calydial.org )

calydial

Mathilde. Prezelin-Reydit

AURAD-Aquitaine

Anne. Kolko

Association pour l'Utilisation du Rein Artificiel en région Parisienne (AURA) Paris

Marie. Lino-Daniel

calydial

Charlotte. Dumas Roque

AURAD-Aquitaine

Pablo. Urena

Association pour l'Utilisation du Rein Artificiel en région Parisienne (AURA) Paris

Philippe. Chauveau

AURAD-Aquitaine

Catherine. Lasseur

AURAD-Aquitaine

Julie. Haesebaert

Université Lyon, Université Claude Bernard Lyon 1, RESHAPE INSERM U1290

Agnes. Caillette-Beaudoin

calydial

\section{Research Article}

Keywords: Chronic kidney disease, Fatigue, Hemodialysis, Quality of life, Patient reported outcome, PROMs

Posted Date: April 28th, 2021

DOI: https://doi.org/10.21203/rs.3.rs-429813/v1

License: (a) (i) This work is licensed under a Creative Commons Attribution 4.0 International License.

Read Full License 


\section{Abstract}

Background: End Stage renal disease (ESRD) and hemodialysis are associated with a decrease in quality of life (QOL). Self-reported QOL symptoms are not always prioritized by the medical team, potentially leading to conflicting priorities with patients. Electronic patient-reported outcome measures (ePROMs) allow physicians to better identify these symptoms. The objective was to describe the prevalence of symptoms self-reported by hemodialysis (HD) patients.

Methods: A multicenter cross-sectional study was conducted in three HD centers. Patients were included if they were 18 years old or over and treated with HD for at least three months in a center. Data were collected by the patient via a self-administered ePROMs questionnaire. Data included patient characteristics, post-dialysis fatigue and intensity, recovery time after a session, perceived stress, impaired sleep the day before the dialysis session, current state of health, and the one-year change.

Results: In total, we included 173 patients with a mean age of 66.2 years, a mean \pm SD hemodialysis duration of $48.9 \pm 58.02$ months. They were mainly treated in self-dialysis unit (67\%) with at least one comorbidity (72.5\%). The prevalence of fatigue was $72.1 \% .66 .4 \%$ had a high level of stress (level B or C). Recovery time was more than 6 hours after a HD session for $24.9 \%$ of patients and $78 \%$ declared they had a better or unchanged health status than the previous year. Sleep disturbance was associated with cardiovascular comorbidities.

Conclusions: Fatigue and stress were the main symptoms reported by HD patients. The patient's care teams should better consider these symptoms.

Trial registration: Commission Nationale de l'Informatique et des Libertés (CNIL): № 2214737V0, Date First Registered: 2019-08-20. The CPP (Patient Protection Committee) Ile-de-France VII (2019-12-26) in accordance with French regulations N ID-RCB: 2019-A01373-54. Date First Registered: 2019-08-19.

All methods were carried out in accordance with the relevant guidelines and regulations.

Informed consent was obtained from all subjects, no subjects were under 18 years of age

\section{Background}

Patients with chronic kidney disease (CKD) treated with hemodialysis (HD) require long-term care with a potentially negative impact on their quality of life (QoL) [1]. Patients treated with hemodialysis have a high symptomatic burden additionally impacting their QoL, which include pain, fatigue and stress [2].

These symptoms are, however, not always considered as a priority focus by the medical team in care of such patients and thus they are not routinely collected despite their significance on the patients $[3,4]$. The lack of focus on QoL from physicians may lead to conflicting medical and treatment priorities between a patient and their care team, and lead to potentially undiagnosed and untreated symptoms. This is especially apparent for patients with end-stage kidney disease (ESKD) $[5,6,7]$. 
The collection of electronic patient-reported outcome measures (ePROMs) is an innovative method to better take these symptoms into consideration [8]. Moreover, ePROMs allow patients to express their symptoms on a regular basis and allow the medical team to adapt treatment plans accordingly [8]. However, the use of ePROMs for CKD patients treated with HD in routine care remains limited $[9,10]$. The objective of the study was to describe the prevalence of symptoms reported by patients treated with hemodialysis using ePROMs. The secondary objective was to explore predictive factors of the presence of the patient reported symptoms.

\section{Methods}

\section{Study design}

A multicenter cross-sectional observational study was conducted in three hemodialysis centers in France (Vienne, Bordeaux and Paris) between January and March 2020. Patients were included if they were aged at least 18 years old and treated with hemodialysis for at least 3 months in one of the participating centers. Patients were excluded if they refused to participate in the study, or could not read or understand French well enough to complete the questionnaires. The study was declared to the data protection authority in France, known as the Commission Nationale de l'Informatique et des Libertés (CNIL), and was approved by the CPP Ile-de-France VII on 26 December 2019 in accordance with French regulations.

\section{Choice of symptoms to collect}

We chose to report the symptoms which were the most frequently reported in a preliminary qualitative study. This qualitative study was conducted to identify relevant symptoms reported by patients and affecting quality of life between dialysis sessions ${ }^{11}$. A total of 20 patients were interviewed by a nephrologist trained to conduct semi-structured interviews. Patients were encouraged to provide examples and expand their answers to collect further details. Interviews were then transcribed and coded with thematic analysis to identify theme and subthemes from the data. Interviews were ceased when no new codes were identified and data saturation was reached. We explored inter-dialysis symptom and we selected the three most frequent symptoms that were fatigue, mental and sleep disorder (Table 1). 
Table 1

Themes and subthemes identified during the preliminary qualitative phase with for patients with chronic kidney disease treated with hemodialysis in the ePROMs study.

\begin{tabular}{|c|c|}
\hline Themes & Subthemes \\
\hline \multirow[t]{2}{*}{ Fatigue } & Feeling tired \\
\hline & Lack of energy \\
\hline \multirow[t]{5}{*}{ Mental symptoms } & Feeling anxious \\
\hline & Feeling irritable \\
\hline & Feeling sad \\
\hline & Feeling nervous \\
\hline & Concern \\
\hline \multirow[t]{2}{*}{ Sleep disorders } & Difficulty falling asleep \\
\hline & Difficulty staying asleep \\
\hline \multirow[t]{5}{*}{ Other symptoms } & Decreased appetite \\
\hline & Decreased sexual desire \\
\hline & Dry mouth \\
\hline & Cramps \\
\hline & Itching \\
\hline
\end{tabular}

\section{Data collected}

Data were collected once by the patient, or with the help of a caregiver if necessary, with a selfadministered ePROMs through an electronic tablet during a HD session or consultation. The collection of data through a tablet was chosen due to the ease of use and simple interface for the patients. Data collected included the presence of post-dialysis fatigue with a binary question (yes/no), its perceived intensity with a visual analog scale ranged from 0 to 10 ( 0 was no perceived intensity and 10 was the most possible perceived intensity) [12], and the recovery time of this symptom after a session as a Likert scale question [13] (Table 2). Perceived stress scale (PSS 10) was questioned using a scale adapted from Cohen and Williamson $[14,15]$. Sleep quality the day before the dialysis session was questioned in the form of a Likert scale format, the current state of health of the patient using a visual analog scale [16], and the one-year change using a Likert scale were also collected. Patients characteristics were described from the patient's medical records (demographics, dialysis situation, BMI, comorbidities, hemoglobin). 
Table 2

Symptom scales chosen for patients with chronic kidney disease treated with hemodialysis in the ePROMs study.

\begin{tabular}{|c|c|c|}
\hline Symptoms & Indicator & Scale \\
\hline \multirow[t]{3}{*}{ Fatigue } & Prevalence & Binary question: Yes/No \\
\hline & Intensity & Visual analog scale from 0 (not tired) to 10 (very tired) \\
\hline & Recovery time & $\begin{array}{l}\text { Likert scale (less than } 2 \text { hours, } 2 \text { to } 6 \text { hours, } 7 \text { to } 12 \text { hours, } \\
\text { more than } 12 \text { hours) }\end{array}$ \\
\hline \multirow[t]{5}{*}{ Stress } & Intensity & $\begin{array}{l}\text { Visual analog scale from } 0 \text { (not stressed) to } 10 \text { (very } \\
\text { stressed) }\end{array}$ \\
\hline & \multirow[t]{4}{*}{ Severity } & Perceived Stress Scale adapted from Cohen and Williamson \\
\hline & & $\begin{array}{l}\text { A ( }(21) \text { : knows how to manage stress and adapt to find } \\
\text { solutions }\end{array}$ \\
\hline & & $\begin{array}{l}\text { B ( } 21 \text { to } 26) \text { : knows to manage stress most of the time but it } \\
\text { is not possible to manage stress in some situations. It is } \\
\text { possible to learn stress management techniques }\end{array}$ \\
\hline & & $\begin{array}{l}C(\geq 27) \text { : does not know how to manage stress and } \\
\text { perception of continuous threat which can negatively impact } \\
\text { life and disease course. }\end{array}$ \\
\hline $\begin{array}{l}\text { Sleep } \\
\text { disorders }\end{array}$ & $\begin{array}{l}\text { Sleep quality the } \\
\text { night before dialysis } \\
\text { compared to other } \\
\text { nights }\end{array}$ & $\begin{array}{l}\text { Likert scale (My sleep is better, my sleep is more or less good, } \\
\text { my sleep is unchanged, my sleep is altered) }\end{array}$ \\
\hline \multirow{2}{*}{$\begin{array}{l}\text { Overall } \\
\text { health } \\
\text { status }\end{array}$} & Current status & $\begin{array}{l}\text { Visual analog scale from } 0 \text { (very poor health) to } 10 \text { (very good } \\
\text { health) }\end{array}$ \\
\hline & $\begin{array}{l}\text { Comparison to one } \\
\text { year before }\end{array}$ & $\begin{array}{l}\text { Likert scale (poorer status, unchanged, more or less improved, } \\
\text { improved) }\end{array}$ \\
\hline
\end{tabular}

\section{Statistical analysis}

We included all patient with eligibility criteria during the study period, our aim was to include all patient during a 3 months period to be representative of patients.

We described continuous variables using medians and interquartile ranges. Numbers and percentages were used for qualitative variables. We first described the prevalence of each ePROM was estimated with $95 \%$ confidence interval. We compared patient's characteristics and ePROMS between the 3 participating centers. Association between ePROMs (recovery time of fatigue ( $\leq 6$-hour versus $>6$-hour), PSS stress level (A versus BC), sleep quality (disrupted versus not disrupted) and patients' characteristics and clinical variables was explored using chi square comparisons or Student's $t$ and Wilcoxon tests according to the nature and distribution of the variables. 
Multivariate logistic regression models were conducted to identify if patients characteristics or clinical variables were associated with recovery time of fatigue (model 1), perceived stress using PSS (model 2) and sleep quality (model 3). Variables included in the model were chosen based on available literature, expert discussion and results of the bivariate analysis. A multivariate regression model was built for each e-PROMS, with the ePROMs as dependent variable, and clinical characteristics (age, gender, dialysis duration, cardiovascular history), denutrition, hemoglobin, duration of haemodialysis session and number of sessions per-week, and the two other e-PROMs as independent variables. Denutrition was defined by at least two of three following criteria: Serum Albumin $<35 \mathrm{~g} / \mathrm{l}$, Serum Prealbumin $<300 \mathrm{mg} / \mathrm{l}, \mathrm{nPCR}<1.2$ $\mathrm{g} / \mathrm{Kg} / \mathrm{d}$. Cardiovascular history was defined by at least one of the following: diabetes, Coronary artery disease, Heart failure, Stroke. A bilateral threshold of $5 \%$ was considered to define the statistical significance. The analysis was performed with SAS 9.1 software.

\section{Results}

In total, 173 patients were included during the study period. The mean age of patient was $66.2 \pm 14.4$ years and majority of patients were males (67.6\%). Furthermore, patients were treated with hemodialysis for a mean total duration of $48.9 \pm 58.02$ months (median 31 months) and were mainly treated in selfdialysis unit (67\%). The mean length of dialysis per week was $11.46 \pm 1.41$ corresponding to $3.09 \pm 0.56$ sessions per week (shown in Table 3 ). 
Table 3

Patients characteristics with chronic kidney disease treated with hemodialysis in the ePROMs study.

\begin{tabular}{|c|c|c|c|c|c|}
\hline & Total & Center 1 & Center 2 & Center 3 & p-value \\
\hline Patients n (\%) & $173(100)$ & $72(41.6)$ & $44(25.4)$ & $57(33)$ & \\
\hline Age mean $( \pm S D)$ & $\begin{array}{l}66.2 \pm \\
14.4\end{array}$ & 71.8 & 58.7 & 64.5 & \\
\hline Sex Male n(\%) & $117(67.6)$ & $50(69.4)$ & $31(70.5)$ & $36(63.2)$ & \\
\hline Dialysis & $48.9(31)$ & $35(26.5)$ & $62.9(30)$ & $56.9(38)$ & $<0.001$ \\
\hline $\begin{array}{l}\text { Duration in months mean } \\
\text { (median) }\end{array}$ & 67.1 & 44.4 & 60.5 & 100 & \\
\hline \multicolumn{5}{|l|}{ Duration of session } & \\
\hline \multicolumn{6}{|c|}{ Number of sessions per week } \\
\hline BMI n (\%) & $10(6.1)$ & $4(5.6)$ & $4(10.5)$ & $2(3.6)$ & \\
\hline$<18$ & $73(44.2)$ & $22(30.6)$ & $22(57.9)$ & $29(52.7)$ & \\
\hline $18-25$ & $82(49.7)$ & $46(63.9)$ & $12(31.6)$ & $24(43.6)$ & \\
\hline \multicolumn{6}{|l|}{$>25$} \\
\hline Comorbidities \% & 15.7 & 20.8 & 21.6 & 5.3 & 0.0285 \\
\hline Undernutrition & 28.4 & 43.1 & 15.8 & 15.6 & $<0.001$ \\
\hline Diabetes & 6 & 9.7 & 5.3 & 1.8 & 0.162 \\
\hline Cerebrovascular disease & 34.3 & 47.9 & 18.4 & 28.1 & 0.004 \\
\hline Coronary artery disease & 21.6 & 31.9 & 5.3 & 19.3 & 0.0047 \\
\hline Peripheral artery disease & 33.7 & 45.1 & 13.2 & 35.1 & 0.0008 \\
\hline Congestive heart failure & 27.5 & 46.1 & 23.7 & 10.5 & 0.0002 \\
\hline \multicolumn{6}{|l|}{ Cancer } \\
\hline Hemoglobin $(\mathrm{g} / \mathrm{dL})$ & $11.3 \pm 1.1$ & $11.8 \pm 1.5$ & $11.5 \pm 0.8$ & $11.4 \pm 1$ & 0.0008 \\
\hline Mean $( \pm S D)$ & $14(8.4)$ & $13(18.1)$ & $0(0)$ & $1(1.7)$ & \\
\hline$<10$ & $117(70.1)$ & $48(66.7)$ & $25(65.8)$ & $44(77.2)$ & \\
\hline $10-12$ & $36(21.6)$ & $11(15.3)$ & $13(34.2)$ & $12(21.1)$ & \\
\hline$>12$ & & & & & \\
\hline
\end{tabular}




\begin{tabular}{|c|c|c|c|c|c|}
\hline & Total & Center 1 & Center 2 & Center 3 & p-value \\
\hline Albumin (g/dL) & $39.6 \pm 5.9$ & $39.2 \pm 3.8$ & $39.7 \pm 3.9$ & $40.2 \pm 2.9$ & \\
\hline Mean $( \pm S D)$ & $21(12.6)$ & $14(19.4)$ & $6(15.8)$ & $1(1.7)$ & \\
\hline$\leq 35$ & $146(87.4)$ & $58(80.6)$ & $32(84.2)$ & $56(98.3)$ & \\
\hline \multicolumn{6}{|l|}{$>35$} \\
\hline Single-pool Kt/V & $\begin{array}{l}1.44 \pm \\
0.34\end{array}$ & $\begin{array}{l}1.59 \pm \\
0.37\end{array}$ & $\begin{array}{l}1.09 \pm \\
0.21\end{array}$ & $\begin{array}{l}1.22 \pm \\
0.25\end{array}$ & \\
\hline & $48(28.9)$ & $12(16.7)$ & $3(8.1)$ & $33(57.9)$ & \\
\hline $\begin{array}{l}\leq 1.2 \\
>1.2\end{array}$ & $118(71.1)$ & 60 (83.3) & $34(91.9)$ & $24(42.1)$ & \\
\hline
\end{tabular}

In terms of comorbidities, $72.5 \%$ of patients had at least one comorbidity which were coronary artery disease (34.3\%), diabetes (28.4\%), cancer (27.5\%) and undernutrition (15.7\%). Expected differences between centers were observed (shown in Table 3). Regarding laboratory test results, $70 \%$ of patients had hemoglobin $(\mathrm{Hb})$ between 10 and $12 \mathrm{~g} / \mathrm{dL}$, and $8 \%$ had $\mathrm{Hb}$ inferior to $10 \mathrm{~g} / \mathrm{dL}$. Moreover, $13 \%$ of patients had their albumin inferior or equal to $35 \mathrm{~g} / \mathrm{dL}$, and $29 \%$ has single-pool Kt/V inferior or equal to 1.2 .

The prevalence of fatigue was $72.1 \%[95 \% \mathrm{Cl}, 64.7-78.7 \%]$ with a mean severity score of $5.84 \pm 2.12$ on a zero to ten scale. Recovery time was more than 6 hours for $24.9 \%$ [95\% $\mathrm{Cl}, 18.6-32 \%]$ of patients. $39 \%$ [95\% $\mathrm{Cl}, 32-47 \%]$ of patients have a stress level $\mathrm{C}$. They did not know how to manage stress and perception of continuous threat which can negatively impact life and disease course. $27.2 \%[95 \% \mathrm{Cl}, 20-$ $35 \%$ ] of patients have a stress level B (They know to manage stress most of the time but it is not possible to manage stress in some situations). The average intensity score was $3.7 \pm 3$ on a zero to ten scale. Sleep quality was disrupted for $14.5 \%$ [95\% Cl, 9.6-20.6\%] of patients. The self-perceived health status of patients was $6.2 \pm 2.12$ (on a zero to ten scale) and $77.5 \%$ [95\% Cl, $70.5-83.5 \%$ ] of patients stated that they had not a worsened health status than the year before (Table 4). No statistical differences were observed between centers for the three e-PROMS. 
Table 4

Patients with chronic kidney disease treated with hemodialysis reported symptoms in the ePROMs study.

\begin{tabular}{|c|c|c|c|c|}
\hline & Total & Center 1 & Center 2 & Center 3 \\
\hline Fatigue n (\%) & $124(72.1)$ & $52(72.2)$ & $30(69.8)$ & $42(73.7)$ \\
\hline Fatigue intensity & $5.8 \pm 2.1$ & $6 \pm 2.4$ & $5.8 \pm 1.9$ & $5.7 \pm 1.9$ \\
\hline Recovery delay (\%) & 42.2 & 38 & 50 & 42.1 \\
\hline$<2$ hours & 32.9 & 32 & 34 & 33.3 \\
\hline $2-6$ hours & 13.3 & 15 & 6.9 & 15.8 \\
\hline 7-12 hours & 11.6 & 15 & 9.1 & 8.8 \\
\hline \multicolumn{5}{|l|}{$>12$ hours } \\
\hline Health status & $6.2 \pm 2.1$ & $6 \pm 2.5$ & $6.2 \pm 1.8$ & $6.5 \pm 1.9$ \\
\hline Health status compared to 1 year before & 40.1 & 40.3 & 39.5 & 40.3 \\
\hline Improved & 8.7 & 11.1 & 9.3 & 5.3 \\
\hline More or less improved & 29.1 & 22.2 & 32.6 & 35.1 \\
\hline Non changed & 22.1 & 26.4 & 18.6 & 19.3 \\
\hline \multicolumn{5}{|l|}{ Altered } \\
\hline Stress intensity & $3.7 \pm 3$ & $3.5 \pm 3.2$ & $3.3 \pm 3$ & $3.8 \pm 2.9$ \\
\hline Stress severity (\%) & 33.5 & 29.2 & 36.4 & 36.8 \\
\hline$A$ & 27.2 & 29.2 & 25 & 26.4 \\
\hline B & 39.3 & 41.6 & 38.6 & 36.8 \\
\hline \multicolumn{5}{|l|}{ C } \\
\hline Sleep quality (\%) & 6.4 & 5.5 & 7 & 7 \\
\hline Improved & 19.8 & 18.1 & 18.6 & 22.8 \\
\hline More or less good & 59.3 & 61.1 & 62.8 & 54.4 \\
\hline Non changed & 14.5 & 15.3 & 11.6 & 15.8 \\
\hline Altered & & & & \\
\hline
\end{tabular}

Results of multivariate analysis are reported in appendixes 1, 2 and 3. Fatigue recovery superior to 6 hours was associated with the decreasing duration of HD sessions (OR:0.15; 95\% $\mathrm{Cl}, 0.04-0.58, \mathrm{p}=$ $0.006)$ and with a higher stress level $(\mathrm{OR}: 2.68 ; 95 \% \mathrm{Cl}, 1.04-6.88, \mathrm{p}=0.041)$. Higher stress level was 
associated with female gender (OR:2.27; $95 \% \mathrm{Cl}, 1.001-5.14, \mathrm{p}=0.05)$ and fatigue recovery superior to 6 hours (OR:2.7; $95 \% \mathrm{Cl}, 1.05-6.92, \mathrm{p}=0.04)$. Sleep disturbance was associated with cardiovascular comorbidities (OR:5.08; $95 \% \mathrm{Cl}, 1.56-16.59, \mathrm{p}=0.007$ ).

\section{Discussion}

In this study, we identified a high prevalence of self-reported fatigue at $72.1 \%$ and important stress at $39.3 \%$ for CKD patients treated with hemodialysis. To our knowledge, this study was the first of its kind conducted in France with questionnaires filled at the healthcare facility via a tablet on describing the use of ePROMs.

Fatigue was the most prevalent symptom identified in our study, in comparison to the other symptoms assessed. The prevalence of $72.1 \%$ of patients was consistent with the range of previous published literature, which presented a figure from $60-97 \%$. These results were additionally similar to the weighted mean prevalence of $71 \%$ estimated in a systematic review $[17,18]$. These results did not differ between centers even though patient characteristics and comorbidities differed.

Items collected from a patient were with a simple binary question and visual analog scale instead of a dedicated measure and thus may not have reflected the specificity of fatigue from patients under hemodialysis. Such specific questionnaire was not available at the time of protocol definition and therefore a generic questionnaire was used. In future studies, items may be collected via the recently published measure SONG-HD questionnaire specifically designed for patients treated with hemodialysis [19]. This innovative tool designed through an international study included several components of fatigue including tiredness, lack of energy and inability to participate in social situations [20]. This tool, however, did not distinguish between interdialytic fatigue and post-dialysis fatigue [21].

In our study, the post-dialysis fatigue through the after-session delay recovery time in hours was chosen to be assessed as expressed by the patient. The recovery time inferior to 6 hours found in the study for $75.1 \%$ of patients were similar compared to an international study where $73 \%$ of patients declared the same timing, as well as a recovery time of more than 12 hours declared by $11.6 \%$ of patients from our study compared to $10 \%$ in the international DOPPS study [22]. Increased fatigue and higher levels of perceived stress were associated in the multivariate analysis indicating the potential interrelation between these two symptoms.

The stress assessment through the perceived stress score seemed to be more informative than the visual analog scale (VAS) to assess its intensity as it allowed to better discriminate patient groups with different stress levels. The two scales are different as the VAS describe the stress at the time of the questionnaire while the PSS includes the stress felt in the past week. Additionally, the analog scale may reflect the stress level more at the time of the questionnaire while the PSS findings may reflect the stress tendency over the past weeks more and thus may be a better estimation of the patient stress level at home. 
On the other hand, results on sleep quality were different to those reported in the literature. While we found only $14.5 \%$ of patients with reported altered sleep, sleep disturbance was reported at weighted mean prevalence of $44 \%$ with a range of $20-83 \%[12,23,24]$ in various countries. The observed difference may be due to the questionnaire used to assess the sleep quality in our study. The questionnaire in our study focused on the sleep quality the night before the dialysis session in comparison to the previous nights, to assess the potential impact of pre-dialysis anxiety on sleep quality. Additionally, these results may be in favor of a limited impact of the dialysis on sleep quality. The difference in results compared with literature is thus explained as those results concerning the disturbance in overall sleep quality for patients treated by hemodialysis in comparison to their situation before the dialysis initiation [25].

The main strengths of this study relied on the cross-sectional and multicenter design from various HD center settings and the use of simple questionnaires to collect data from patients through a tablet directly at patient side. The collection of data from patients during a consultation or HD session through a tablet device also allowed to not have missing data that could have weaken the interpretation of the results. On the other hand, the answers provided by patients may as well have been influenced by the settings in which they were to reply.

Despite significant differences in patient characteristics from the three centers including age, comorbidities or type of dialysis, no differences were found on the prevalence of the various PROMs, in favor of internally coherent results. The study population was not matching with the population profile of the French Renal Epidemiology and Information Network (REIN) $[26,27,26]$ and consequently, in terms of comorbidities, coronary artery disease, congestive heart failure and cancer comorbidities the prevalence were higher in our study population. Contrarily, prevalence of diabetes and cerebrovascular disease were lower compared to REIN. This difference may lead to a selection bias and therefore our results may not be applicable to all hemodialysis patients in France. The 3 centers in our study have different characteristics, and no statistical differences were observed between centres for the three e-PROMS.

The main limitations of this study included the observational design, limited number of patients included, and the absence of linkage of PROMs with clinical outcomes such as cardiovascular events, hospitalizations or mortality. However, the objective was to describe the symptoms of patients and not to explain these symptoms with their clinical situation or outcomes.

Nonetheless, meta-analysis of oncology trials identified baseline fatigue as an independent prognostic factor for overall survival above performance status and quality of life in oncology patients, recommending collecting this information in routine oncology care for patient stratification [29]. Due to the clinical impact of fatigue on daily QoL of patients undergoing hemodialysis, it may be however relevant to consider the presence of reported fatigue in such patients to be a clinically relevant item to consider as itself, despite the need for further research in this area [30]. Additionally, recent studies identified an association between fatigue and all-cause mortality in those patients as well as between frailty and worse health related QoL $[22,31,32]$. 
To improve daily routine care of CKD patients treated with HD, the collection and integration of ePROMs into the care plan could be promoted in a standardized approach. Such efforts are currently being conducted in various countries or regions such as in Ontario, Canada with the Edmonton Symptom Assessment System Revised for routine PROMs collection in hemodialysis routine care and should be encouraged as well in France ${ }^{33}$. In this regard, the French Society of Nephrology, Dialysis and Transplant (SFNDT) published in 2020 a new guideline recommending the use of EuroQol 5D and 12-Item Short Form Health Survey for outcome measures and e-Satis national public system for measuring patient satisfaction [34, 35].

Dedicated software linking patient registries in hemodialysis, collection of ePROMs for remote patient monitoring and measures of patient satisfaction may thus be used to ease and improve routine care as well as clinical and epidemiological research ${ }^{36}$.

\section{Conclusion}

In conclusion, Fatigue and stress were the main symptoms reported by HD patients. The prevalence of fatigue was $72.1 \% .66 .2 \%$ of patients have a high level of stress ( $27.2 \%$ level B and $39 \%$ level C). The 3 centers in our study have different characteristics, and no statistical differences were observed between centres for the three e-PROMS. These sympthoms could have an impact on the quality of life of patients. The patient's care teams should better consider these symptoms.

The clinical use of PROMs has been most extensively studied in the oncology literature, in which randomized trials have reported improved outcomes in several areas, including patient-provider communication, quality of life, care satisfaction, and even survival. However, to derive such benefits from the routine use of PROMs, they must be incorporated into clinical care. A renal ePROM system can play a supportive role in the routine clinical management of ESRD patients and improve the patient centred care. Electronic PROMs records as well as various other electronic methods of communication between the clinician and patient may serve to accelerate the trajectory toward patient-centered care using patientreported outcomes .

\section{Abbreviations}

ESRD: End Stage renal disease

QOL: Quality Of Life

ePROMs : Electronic Patient-Reported Outcome Measures

PROMs: Patient-Reported Outcome Measures

HD: Hemodialysis

CKD: Chronic Kidney Disease 
ESKD: End-Stage Kidney Disease

Hb: Hemoglobin

PSS 10: Perceived Stress Scale

VAS: Visual Analog Scale

REIN: French Renal Epidemiology and Information Network

\section{Declarations}

Ethics approval and consent to participate: The study was declared to the data protection authority in France, known as the Commission Nationale de l'Informatique et des Libertés ( $\left.\mathbf{N}^{\circ} 2214737 \mathrm{~V} 0\right)$, (CNIL), and was approved by the CPP Ile-de-France VII (N ID-RCB: 2019-A01373-54) on 26 December 2019 in accordance with French regulations.

All methods were carried out in accordance with the relevant guidelines and regulations.

Informed consent was obtained from all subjects, no subjects were under 18 years of age

Consent for publication: Not applicable

Availability of data and materials: The datasets used and/or analysed during the current study are available from the corresponding author on reasonable request.

Competing interests: Authors declare there are no competing interests

Funding: No funding declared

Author's contributions: AG, JH analyzed and interpreted the patient, MPR, AK, PC, CL, ACB were major contributor in writing the manuscript. All authors read and approved the final manuscript.

eProms study investigators : AG, MPR, MLD, AK, CD, PU

Acknowledgements: The authors thank the three centers and all the team M.Grange, F BelkahlaDelabruyere, F.Leveque (education nurse), AL.Camaroque (project manager) and S.Racanière (person in charge of relations with users) and AcaciaTools for providing their medical editing and reviewing services.

\section{References}

1. Theofilou P. Quality of life in patients undergoing hemodialysis or peritoneal dialysis treatment. J Clin Med Res. 2011 May 19;3(3):132-8. 
2. Wyld M, Morton RL, Hayen A, Howard K, Webster AC. A systematic review and meta-analysis of utility-based quality of life in chronic kidney disease treatments. PLoS Med. 2012;9(9):e1001307. doi: 10.1371/journal.pmed.1001307. Epub 2012 Sep 11.

3. Weisbord SD, Fried LF, Mor MK, Resnick AL, Unruh ML, et al. Renal provider recognition of symptoms in patients on maintenance hemodialysis. Clin J Am Soc Nephrol. 2007 Sep;2(5):960-7.

4. Claxton RN, Blackhall L, Weisbord SD, Holley JL. Undertreatment of symptoms in patients on maintenance hemodialysis. J Pain Symptom Manage. 2010 Feb;39(2):211-8.

5. Chong K, Unruh M. Why does quality of life remain an under-investigated issue in chronic kidney disease and why is it rarely set as an outcome measure in trials in this population? Nephrol Dial Transplant. 2017 Apr 1;32(suppl_2):ii47-ii52

6. Morton RL, Tong A, Howard K, Snelling P, Webster AC. The views of patients and carers in treatment decision making for chronic kidney disease: systematic review and thematic synthesis of qualitative studies. BMJ. 2010 Jan 19;340:c112.

7. Morton RL, Snelling P, Webster AC, Rose J, Masterson R, Johnson DW, Howard K. Factors influencing patient choice of dialysis versus conservative care to treat end-stage kidney disease. CMAJ. 2012 Mar 20;184(5):E277-83.

8. Dobrozsi S, Panepinto J. Patient-reported outcomes in clinical practice. Hematology Am Soc Hematol Educ Program. 2015;2015:501-6.

9. Anderson NE, Calvert M, Cockwell P, Dutton M, Aiyegbusi OL, Kyte D. Using patient-reported outcome measures (PROMs) to promote quality of care in the management of patients with established kidney disease requiring treatment with haemodialysis in the UK (PROM-HD): a qualitative study protocol. BMJ Open. 2018 Oct 28;8(10):e021532.

10. Anderson NE, Calvert M, Cockwell P, Dutton M, Kyte D. The Use of Patient-Reported Outcomes in Patients Treated With Maintenance Hemodialysis: A Perspective. Am J Kidney Dis. 2019 Sep;74(3):399-406.

11. Tong A, Sainsbury P, Craig J. Consolidated Criteria for Reporting Qualitative Research (COREQ): a 32item checklist for interviews and focus groups. Int J Qual Health Care. 2007;19(6):349-357.

12. Lee KA, Hicks G, Nino-Murcia G. Validity and reliability of a scale to assess fatigue. Psychiatry Res. 1991 Mar;36(3):291-8.

13. Aaronson LS, Teel CS, Cassmeyer V, Neuberger GB, Pallikkathayil L, Pierce J, Press AN, Williams PD, Wingate A. Defining and measuring fatigue. Image J Nurs Sch. 1999;31(1):45-50.

14. Cohen S, Kamarck T, Mermelstein R. A global measure of perceived stress. J Health Soc Behav. 1983 Dec;24(4):385-96. PMID: 6668417.

15. Cohen S, Williamson G, Spacapan S, Oskamp S. Perceived Stress in a Probability sample of the United States. The social Psychology of Health : Claremont symposium on Applied social psychology. 1988

16. Atkinson MJ, Lennox RD. Extending basic principles of measurement models to the design and validation of Patient Reported Outcomes. Health Qual Life Outcomes. 2006 Sep 22;4:65. 
17. Jhamb M, Weisbord SD, Steel JL, Unruh M. Fatigue in patients receiving maintenance dialysis: a review of definitions, measures, and contributing factors. Am J Kidney Dis. 2008 Aug;52(2):353-65. doi: 10.1053/j.ajkd.2008.05.005.

18. Murtagh FE, Addington-Hall J, Higginson IJ. The prevalence of symptoms in end-stage renal disease: a systematic review. Adv Chronic Kidney Dis. 2007;14(1):82-99

19. Ju A, Teixeira-Pinto A, Tong A, Smith AC, Unruh M, et al. Validation of a Core Patient-Reported Outcome Measure for Fatigue in Patients Receiving Hemodialysis: The SONG-HD Fatigue Instrument. Clin J Am Soc Nephrol. 2020 Nov 6;15(11):1614-1621.

20. Ramer SJ, Scherer JS. Moving the Science of Patient-Reported Outcome Measures Forward: Measuring Fatigue in Hemodialysis Patients. Clin J Am Soc Nephrol. 2020 Nov 6;15(11):1546-1548.

21. Sondergaard H. Fatigue While Undergoing Long-Term Hemodialysis. Clin J Am Soc Nephrol. 2020 Nov 6;15(11):1539-1540.

22. Rayner HC, Zepel L, Fuller DS, Morgenstern H, Karaboyas A, et al. Recovery time, quality of life, and mortality in hemodialysis patients: the Dialysis Outcomes and Practice Patterns Study (DOPPS). Am J Kidney Dis. 2014 Jul;64(1):86-94.

23. Mirghaed MT, Sepehrian R, Rakhshan A, Gorji H. Sleep Quality in Iranian Hemodialysis Patients: A Systematic Review and Meta-analysis. Iran J Nurs Midwifery Res. 2019 Nov 7;24(6):403-409.

24. Shen Q, Huang X, Luo Z, Xu X, Zhao X, He Q. Sleep quality, daytime sleepiness and health-related quality-of-life in maintenance haemodialysis patients. J Int Med Res. 2016 Jun;44(3):698-709.

25. Nimmo A, Bell S, Brunton C, Campbell J, Doyle A, MacKinnon B, Peel RK, Robertson S, Shilliday I, Spalding E, Traynor JP, Metcalfe W; Scottish Renal Registry. Collection and determinants of patient reported outcome measures in haemodialysis patients in Scotland. QJM. 2018 Jan 1;111(1):15-21.

26. Lassalle M, Monnet E, Ayav C, Hogan J, Moranne O, Couchoud C; REIN registry. 2017 Annual Report Digest of the Renal Epidemiology Information Network (REIN) registry. Transpl Int. 2019 Sep;32(9):892-902.

27. Couchoud C, Gharbi MB. Advocacy for renal replacement therapy: the role of renal registries. Clin Kidney J. 2020 Jul 29;13(5):742-744.

28. Agence de la biomédecine. Registre français des traitements de suppléance de l'insuffisance rénale chronique Rapport 2018. Accessible at: https://www.agencebiomedecine.fr/IMG/pdf/rapport_rein_2018_v2.pdf. Last accessed on 1 December 2020.

29. Sloan JA, Liu H, Satele DV, Puttabasavaiah S, Kaur JS, Hubbard J, Dueck A, Stella PJ, Singh JA. Prognostic significance of baseline fatigue for overall survival: A patient-level meta-analysis of 43 oncology clinical trials with 3915 patients. Trends Cancer Res. 2017;12:97-110.

30. Jacobson J, Ju A, Baumgart A, Unruh M, O'Donoghue D, et al. Patient Perspectives on the Meaning and Impact of Fatigue in Hemodialysis: A Systematic Review and Thematic Analysis of Qualitative Studies. Am J Kidney Dis. 2019 Aug;74(2):179-192.

31. Nixon AC, Bampouras TM, Pendleton N, Mitra S, Brady ME, Dhaygude AP. Frailty is independently associated with worse health-related quality of life in chronic kidney disease: a secondary analysis 
of the Frailty Assessment in Chronic Kidney Disease study. Clin Kidney J. 2019 Apr 30;13(1):85-94.

32. Picariello F, Norton S, Moss-Morris R, Macdougall IC, Chilcot J. Fatigue in Prevalent Haemodialysis Patients Predicts All-cause Mortality and Kidney Transplantation. Ann Behav Med. 2019 May 3;53(6):501-514.

33. Evans JM, Glazer A, Lum R, Heale E, MacKinnon M, Blake PG, Walsh M. Implementing a PatientReported Outcome Measure for Hemodialysis Patients in Routine Clinical Care: Perspectives of Patients and Providers on ESAS-r:Renal. Clin J Am Soc Nephrol. 2020 Sep 7;15(9):1299-1309.

34. Ayav C, Couchoud C, Sautenet B, Lobbedez T, Sens F, Moranne O; Commission épidémiologie et santé publique de la Société francophone de néphrologie, dialyse et transplantation. Le recueil en routine de données de santé perçue à l'ère du paiement à la qualité : préconisations de la Commission épidémiologie et santé publique de la SFNDT [Routine collection of perceived health data in the era of payment for quality: Recommendations by the Epidemiology and public health commission of the SFNDT]. Nephrol Ther. 2020 Aug 1:S1769-7255(20)30102-4.

35. Gloanec M, Capuano F, Sainte-Croix D, May-Michelangeli L. L'enquête nationale e-Satis, mesurer la satisfaction et l'expérience des patients. 2018 Oct;63(829):23-26.

36. Whitlow M, Wallace E. Remote Patient Monitoring: An Important Tool in Advancing Home Dialysis. Kidney Med. 2019 Oct 30;1(6):327-

\section{Supplementary Files}

This is a list of supplementary files associated with this preprint. Click to download.

- ArticleappendixBMC.docx 